\section{Greek archaeomagnitudes}

RELIABLE determination of the ancient geomagnetic field intensity is difficult; any new approach, such as that of Walton ${ }^{1}$, is to be welcomed. Although the method is new and complex, it does not follow that it necessarily gives reliable answers, particularly as its validity rests, on various theoretical assumptions about the behaviour of the magnetic carriers. We consider that Walton's dismissal of the linearity test in the commonly used Thellier technique is premature and insecurely founded. Certainly, this technique always needs to be carried out meticulously, as emphasized by Thellier, otherwise erroneous results are obtained that can, if taken at face value, lead to the supposition of rather exotic behaviour by the geomagnetic intensity in the past. Hence, Walton's finding that his earlier determinations using the Thellier technique were unreliable does not mean that all Thellier results are suspect.

In any linearity test the critical question is 'How linear is linear?' and in the examples referred to by Walton, it may well be that the criteria used were not sufficiently strict. On the other hand, we have confirmed the effectiveness of reliability criteria, where they are stringently applied, by re-examining our recent Thellier results ${ }^{2}$ for the second millennium BC; we have remeasured several of our samples using the coercivity monitoring technique developed by Shaw ${ }^{3}$ and find that the agreement is good. In this method, the coercivity spectrum of the natural remanent magnetization (NRM, the ancient magnetization) is compared with that of the thermoremanent magnetization (TRM, the magnetization acquired on cooling after the laboratory heating); changes in shape indicate that the laboratory heating has caused mineral alteration and there is risk of error. Also, the coercivity spectrum of an acquired remanent magnetization (ARM, magnetization acquired from a weak steady field in the presence of a strong alternating field) given before heating is compared with that of an ARM given after heating; as well as spectrum shape, this monitors any increase or decrease in the magnetic carriers in each coercivity interval, thus providing a built-in quantitative measure of the magnetic alteration. In the basic Shaw technique the ancient intensity is obtained from the NRM/TRM ratio evaluated from coercivity intervals for which there is no change in ARM strength. In later developments ${ }^{4,5}$ it has been shown that, even if alteration occurs, the ARM ratio can be used to correct the NRM/TRM ratio, at least for coercivity intervals $>100 \mathrm{mT}$.

We have now used the Shaw technique, or one of its variants, on eleven samples from several of the sites in ref. 2 (see Table 1). There is agreement with the Thellier values to within $15 \%$ for nine of the samples; seven of these are within $10 \%$ with the Shaw values on average $5 \%$ lower than the Thellier values. The two remaining samples gave inconsistent results for different coercivity intervals, although always within $\pm 25 \%$ of the Thellier value. These are our first results using the Shaw technique and, because there is scope for improvement in our facilities, we consider that good confirmation of the validity of the Thellier results has been obtained. Also, we have used the ARM technique on subsidiary cores (19 samples), with intervening heatings to various of the temperature steps used in the Thellier determination. In this way we can determine whether or not alteration has set in by the upper temperature limit of accepted Thellier data; in no case has the ARM change at that limit been $>6 \%$. These tests justify our confidence in the results of ref. 2 .

Finally, regarding the alteration test of comparison between two measurements made in zero field, suggested by Walton for the Thellier method, we note that his procedure monitors only those carriers having blocking temperatures greater than

Table 1 Comparison of Shaw and Thellier techniques

\begin{tabular}{|c|c|c|c|c|}
\hline \multirow{2}{*}{$\begin{array}{l}\text { Presumed } \\
\text { date } B C\end{array}$} & \multirow{2}{*}{$\begin{array}{l}\text { Sample } \\
\text { location }\end{array}$} & \multirow{2}{*}{$\begin{array}{l}\text { Intensity } \\
\text { ratio } \\
\text { (Thellier) }\end{array}$} & \multicolumn{2}{|c|}{ Ancient intensity $(\mu \mathrm{T})$} \\
\hline & & & Thellier & Shaw \\
\hline $1550-1500$ & Apheq, Israel & 1.06 & 45 & 43 \\
\hline $1550-1500$ & Apheq, Israel & 1.15 & 49 & 48 \\
\hline $1504-1492$ & Karnak, Egypt & 1.17 & 45 & 40 \\
\hline $1250-1150$ & Karnak, Egypt & 1.51 & 58 & 57 \\
\hline $1250-1150$ & Karnak, Egypt & 1.53 & 59 & 57 \\
\hline $1150-1075$ & Kition, Cyprus & 1.62 & 72 & 71 \\
\hline $1100-950$ & Karnak, Egypt & 1.52 & 59 & 51 \\
\hline $1100-950$ & Karnak, Egypt & 1.52 & 59 & 61 \\
\hline $1050-1000$ & Kouklia, Cyprus & 1.53 & 68 & 68 \\
\hline
\end{tabular}

The Thellier results are from ref. 2 ; the intensity ratio quoted is $F_{\mathrm{A}} / F_{\mathrm{D}}$, where $F_{\mathrm{A}}$ is the ancient intensity and $F_{\mathrm{D}}$ is the intensity at the site attributable to an axial centred geomagnetic dipole of present-day strength $\left(8 \times 10^{22} \mathrm{~A} \mathrm{~m}^{2}\right)$.

the magnetization temperature; on the other hand, the in-field measurement is also affected by carriers having lower blocking temperatures. Our experience of comparing demagnetization curves before and after heating indicates that alteration can occur in some blocking temperature ranges without affecting others. A much better test is to compare two in-field measurements, but tests of this type can never give conclusive proof that alteration has not occurred because of the probability that it occurs rapidly and is effectively complete during the first stage of a given temperature step. These comments apply equally to the Walton method.

M. J. AITKEN

A. L. Allsop

G. D. BUSSELL

M. B. WINTER

Research Laboratory for Archaeology,

Oxford University,

6 Keble Road,

Oxford OX1 $3 Q J, U K$

1. Walton, D. Nature 310, 740-743 (1984).

2. Aitken, M. J., Altsop, A. L., Bussell, G. D. \& Winter, M. B. Nature 310, 305-306 (1984)

3. Shaw, J. Geophys. J. R. astr. Soc. 39, 133-141 (1974)

4. Kono, M. Geophys. J. R. astr. Soc. 54, 241-261 (1978).

5. Rolph, T. C. \& Shaw, J. Geophys, J. R. astr. Soc. 80, 773-78 (1985).

WALTON REPLIES-There is quite a clear disagreement between recent results for Greece ${ }^{1}$ and those of Aitken et al. ${ }^{2}$.

I have published two sets of archaeomagnetic intensity measurements for Greece. The original data ${ }^{3}$ also show the increase in intensity that Aitken et al. are proposing to use for archaeomagnetic dating. Unfortunately, the old data in ref. 3 are wrong, which prompted the study in ref. 1. This later study showed that the error was caused by mineral alteration at the higher measurement temperatures. A few samples that showed no evidence of alteration did not show an increase in intensity. It was possible to correct for a small degree of alteration; if the effects of alteration were retained, the increase in intensity referred to above was present in the high temperature points but not at low temperatures. On correction, all the points at all temperatures were consistent, within the experimental accuracy, and the increase disappeared.

The experiments reported in ref. 3 used a technique that did not differ substantially from that used by Aitken et al. ${ }^{2}$, but Aitken et al. $^{2}$ express reservations about the technique used in ref. 1 . It is important, however, to recognize that in all three methods the ancient intensity is obtained by the same method, thermal demagnetization and magnetization, differing only in the test used for alteration.

More specifically, the method used by Aitken $e t a l^{2}$, and initially by myself, 